\title{
Desejo de engravidar e doença psiquiátrica
}

Margarida Mesquita*

\section{RESUMO}

Este relato pretende evidenciar duas questões: o diagnóstico de pseudociese e de patologias associadas e a legitimidade do médico para interferir na decisão de engravidar de uma utente.

Tratou-se de um desafio clínico com várias vertentes controversas; o perfil da utente criou dificuldades ao médico de família e ao sistema; a avaliação familiar revelou dados importantes para a interpretação dos problemas e surgiram questões éticas para as quais não se encontrou consenso entre pares.

Relata-se o caso de uma mulher de 43 anos. Apresenta-se na consulta convicta de estar grávida, com amenorreia e sintomas que associa à gravidez. Com exame objectivo normal, são-lhe pedidos, sequencialmente, DIG, ecografia obstétrica e doseamentos hormonais que se revelam normais e excluem gravidez. Aos 3 meses de amenorreia, a utente mantém a mesma conviç̧ão, as queixas, e «sente o bébé a mexer». Manifesta, entretanto, um intenso desejo de engravidar e pede a opinião do Médico de Família.

Esta nulípara é viúva e reformada, pertence à classe média-baixa de Graffard, e vive com o pai e com o companheiro recente, ambos com problemas de abuso do álcool. Tem antecedentes familiares e pessoais de patologia psiquiátrica grave. Recorre a cerca de 15 consultas anuais no Centro de Saúde e a consultas frequentes fora do Serviço Nacional de Saúde. Mantém uma atitude manipuladora e transfere para o médico a responsabilidade sobre a sua saúde.

O diagnóstico da perturbação psiquiátrica subjacente a este episódio revelou-se controverso pois a pseudociese pode ser encarada ou como um distúrbio somatoforme isolado, ou, dados os antecedentes psiquiátricos, um delírio enquadrado numa perturbação de personalidade borderline. Estas duas hipóteses determinam, à partida, atitudes muito diferentes perante a possibilidade de uma gravidez.

As atitudes a tomar perante os vários desafios deste caso foram discutidas entre pares, sem consenso.

Palavras-chave: Falsa Gravidez; Pseudociese; Desejo de Engravidar; Disfunção Familiar; Aconselhamento Pré-Concepcional; Perturbação da Personalidade borderline.

\section{INTRODUÇÃO}

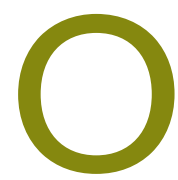

relato deste caso assenta em quatro motivos fundamentais: tratou-se de um desafio clínico com várias vertentes controversas; o perfil da utente criou dificuldades ao médico de família (MF) e ao sistema; a avaliação familiar revelou dados importantes para a interpretação dos problemas e foram levantadas questões éticas para as quais não se encontrou consenso entre pares.

No sentido de facilitar e melhor orientar a leitura deste relato, optou-se por denominar a utente pelo nome fictício de «Arminda» e por atribuir números de ordem (numeração romana) às oito consultas relatadas.

* Médica Interna de Medicina Geral e Familiar Centro de Saúde do Entroncamento

\section{DESCRIÇÃO DO CASO}

Arminda é uma mulher de 43 anos de idade, raça caucasiana, viúva e reformada da profissão de empregada de limpezas. Natural de uma aldeia do concelho da Sertã, viveu numa aldeia do concelho de Tomar até aos 35 anos, altura em que casou e passou a residir na cidade do Entroncamento.

Esta mulher tem a seguinte lista de problemas:

- Asma, desde os 16 anos;

- Síndroma do intestino irritável, desde os 26 anos;

- Perturbação de ansiedade e depressão major, desde os 36 anos;

- Gonartrose bilateral e alterações degenerativas da coluna vertebral, desde os 40 anos.

Os vários problemas motivaram a reforma por incapacidade aos 41 anos. 
Todos os problemas descritos mantêm-se activos e justificam a necessidade de terapêutica farmacológica com:

- Salmeterol $50 \mu$ g e fluticasona $100 \mu$ g inalados $2 x /$ dia

- Brometo de otilónio $40 \mathrm{mg}$ p.o. em períodos de agravamento dos sintomas gastrointestinais

- Lorazepam 2,5 mg/dia p.o.

- Valproato de sódio $500 \mathrm{mg} / \mathrm{dia}$ p.o.

- Buspirona $10 \mathrm{mg} /$ dia p.o.

- AINE's tópicos e p.o. em períodos de agravamento das dores osteoarticulares.

Abandonou as tomas de risperidona e sertralina cerca de dois meses antes do início da situação relatada. As prescrições de lorazepan, buspirona e valproato de sódio foram da iniciativa do Psiquiatra a quem a utente recorre fora do Sistema Nacional de Saúde (SNS).

Da história familiar, é de realçar:

- Mãe com esquizofrenia, depressão e suicídio consumado aos 34 anos;

- Tia materna com doença neuropsiquiátrica, demência antes dos 50 anos e morte aos 63 anos por acidente vascular cerebral (AVC);

- Pai com hipertensão não controlada, abuso do álcool e comportamento agressivo associado à ingestão alcoólica;

- Tio paterno falecido com neoplasia prostática;

- Tio paterno falecido com neoplasia colorrectal; No que respeita ao Planeamento Familiar, a utente é assídua nas consultas e cumpre os rastreios previstos. Viúva desde os 36 anos, nunca engravidou. Mantém relações esporádicas não protegidas com parceiros que reconhece, por vezes, não conhecer bem. Por várias vezes iniciou contracepção oral mas descontinuou sempre, dados os efeitos laterais dos fármacos ou a fugacidade dos relacionamentos.

Sobre o perfil de utilização dos recursos de saúde, realça-se que recorre a uma média de 15 consultas/ano no centro de saúde (CS), vai trimestralmente a uma consulta de Psiquiatria fora do SNS e, sempre que considera necessário, vai a consultas de outras especialidades, fora do SNS. Traz, depois, à consulta no CS os múltiplos pedidos de exames complementares de diagnóstico, os exames efectuados e informação sobre os novos fármacos prescritos.

Na consulta, apresenta múltiplas e sempre renovadas queixas, com sintomas muito focados no aparelho genital. A maioria das queixas não tem tradução no exame objectivo.

Manifesta frequentemente preocupação com o cancro e com as infecções sexualmente transmitidas (IST), apesar de manter comportamentos de risco. Pediu, pelo menos uma vez (no CS), as serologias referentes às IST.

Perante o MF apresenta-se sedutora, manipuladora e pede uma atitude "paternalista» («o médico é quem a pode ajudar!»; «o médico é que sabe o melhor para a sua saúde»; «faz tudo como o médico disser»).

Aparenta cumprir as prescrições de terapêutica farmacológica crónica e renova o receituário periodicamente na nossa consulta.

O início deste caso dá-se quando a Arminda recorre a uma consulta não programada (I), convicta de estar grávida. Numa consulta de Planeamento Familiar, cerca de 3 meses antes desta consulta (I), referiu ter iniciado nova relação «séria» e foi-lhe prescrita anticoncepção oral. ${ }^{23}$ Terá tomado a primeira carteira de comprimidos, ao fim da qual a hemorragia de privação não terá surgido. Concluiu estar grávida e cessou as tomas.

Na consulta (I), apresenta-se com dois meses de amenorreia e com sintomas que associa inequivocamente à sua gravidez:

- Apetite aumentado para alimentos específicos («desejos»);

- Náuseas com o apetite mantido;

- Aumento do volume mamário, tensão mamária e aumento da sensibilidade dos mamilos;

- Aumento do volume abdominal;

- Poliúria.

Na anamnese, excluem-se outros sintomas de infecção urinária. O exame objectivo é sobreponível ao efectuado em consultas anteriores, sem sinais de patologia e com manutenção do peso. O exame sumário da urina com tira reactiva revela-se normal. À avaliação, considera-se a hipótese de gravidez com 8 semanas de evolução. São pedidos DIG e ecografia obstétrica transvaginal para datação da gravidez e é planeada uma Consulta de Saúde Materna.

A Arminda volta passadas duas semanas, mas pede uma consulta urgente (II): os exames efectuados excluíram a hipótese de gravidez, completou dois meses e meio de amenorreia, «sente o bebé a mexer», e mantém as queixas da consulta anterior (I).

O exame físico mantém-se inalterado. Na avaliação, 
considera-se a amenorreia por esclarecer e a hipótese de pseudociese.

A Arminda foi, entretanto, ao seu Psiquiatra, que se mostrou «alarmado» com a situação. O colega pediu uma extensa lista de exames laboratoriais e uma nova ecografia e Arminda pede-nos a transcrição dos pedidos do Psiquiatra para guias do SNS.

Porque a maior parte das análises pedidas seriam repetidas de estudos anteriores ou são consideradas inapropriadas nesta fase da avaliação do problema, contrariam-se as expectativas da utente e pedem-se apenas os doseamentos hormonais (FSH, LH; estrogénio, progesterona, DHEA, prolactina e TSH). ${ }^{1}$ Mesmo após a devida explicação, a utente manifesta a sua insatisfação por não ter sido transcrita a totalidade das análises pedidas.

Passadas novas duas semanas, a Arminda volta para mostrar as análises (III). Os doseamentos hormonais encontram-se dentro dos limites da normalidade para uma mulher em idade fértil. Mantém as queixas das consultas anteriores. O exame objectivo mantém-se inalterado. Na avaliação, mantém-se a hipótese de pseudociese e a amenorreia por esclarecer, com a hipótese de gravidez excluída. O valproato de sódio pode provocar irregularidades menstruais e amenorreia secundária. ${ }^{24}$

Explica-se cuidadosamente à utente que não está grávida. Porque esta mantém a sua vida sexual activa e se encontra em risco para uma gravidez não desejada, prescreve-se anticoncepção oral. ${ }^{23} \mathrm{~A}$ utente mostra relutância em tomar um progestativo isolado, ${ }^{1}$ atitude que seria mais correcta para a continuação do estudo da amenorreia. Tendo em consideração a sua experiência anterior de anticoncepção e de efeitos laterais indesejáveis, aceita cumprir a toma de uma combinação específica de etinilestradiol 0,03 $\mu \mathrm{g}$ + drospirenona $3 \mathrm{mg}$.

Passado um mês, a Arminda volta à consulta (IV). Tem hemorragia de privação e refere já não acreditar na sua gravidez. Entretanto recorreu ao Serviço de Urgência do Hospital Distrital de Castelo Branco por continuar a «sentir o bebé a mexer». Lá, repetiu DIG e ecografia, com resultados sobreponíveis e nova exclusão da hipótese de gravidez.

Porque, em termos psiquiátricos, a pseudociese equivale a um problema somatoforme e porque a utente recorre muitas vezes à consulta, sempre com múlti- plas queixas inespecíficas, faz-se avaliação familiar.

A vida desta mulher tem episódios muito marcantes que se correlacionam com os sucessivos estados patológicos (ver Quadro I).

Quando tinha nove anos de idade, a sua mãe, com esquizofrenia, comete suicídio: a Arminda é forçada a abandonar os estudos no quarto ano do ensino básico para cuidar da casa e do pai, com quem mantinha uma relação escassa. Para além do luto, dá-se o isolamento social. Quando tinha 16 anos, o pai casa de novo e a Arminda inicia uma relação conflituosa com a sua madrasta. Nessa altura, inicia crises de dispneia relacionadas com o choro e a ansiedade e é-lhe diagnosticada asma. Aos 35 anos casa contra a vontade dos sogros. Começa, nessa altura, a tomar ansiolíticos e agravam-se as alterações do trânsito intestinal. Fica viúva aos 36 anos, 7 meses após o seu casamento, quando o marido sofre acidente de viação. Os sogros reclamam a posse da casa do casal, entretanto paga pelo seguro, num pro-

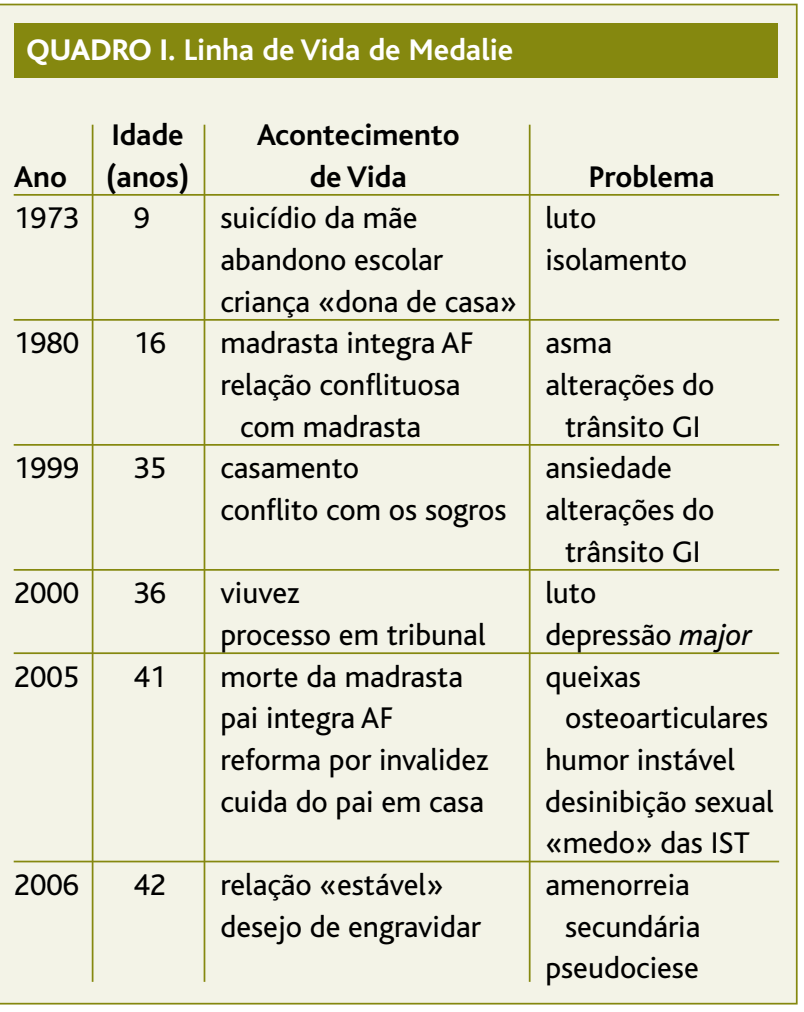

Representação esquemática da Linha de Vida de Medalie da utente. Há correlação entre os vários acontecimentos de vida e a maior parte das situações patológicas. Legenda: GI - gastrointestinal; AF - agregado familiar; IST - infecções sexualmente transmissíveis. 
cesso em tribunal que se arrasta durante cinco anos. Durante este período, o processo de luto da Arminda é agravado e é-lhe diagnosticada depressão reactiva $m a$ jor. Os sintomas de apatia e anedonia e os delírios de doença e de vazio acabam por obrigar a internamento durante 15 dias no Serviço de Psiquiatria do Hospital Egas Moniz, a seguimento em consulta mensal no Hospital Júlio de Matos durante um ano e meio (até aos 38 anos) e à toma de anti-psicóticos e vários antidepressivos até aos 42 anos, pouco antes do início deste relato.

Aos 41 anos, a madrasta morre. O pai, viúvo, muda-se para o apartamento da filha e os seus problemas de abuso do álcool e agressividade agravam-se. A Arminda reforma-se por invalidez da profissão de empregada de limpezas dados os seus problemas osteoarticulares (SIC), e passa a tratar do pai, em casa, a tempo inteiro.

É nesta altura que a Arminda entra para a lista de utentes do actual médico de família.

Apresentava flutuações do humor, com episódios de desinibição sexual e manifestava grande preocupação com o cancro e as infecções sexualmente transmitidas.

Tentou-se completar um genograma, mas a Arminda não sabia fornecer a maior parte das informações sobre os seus familiares. Para além da sua irmã que reside em Lisboa com o marido e sobrinho, com os quais mantém uma relação muito boa, a Arminda mantém uma relação escassa com o pai e não se relaciona com mais nenhum dos seus familiares ainda vivos, dos quais

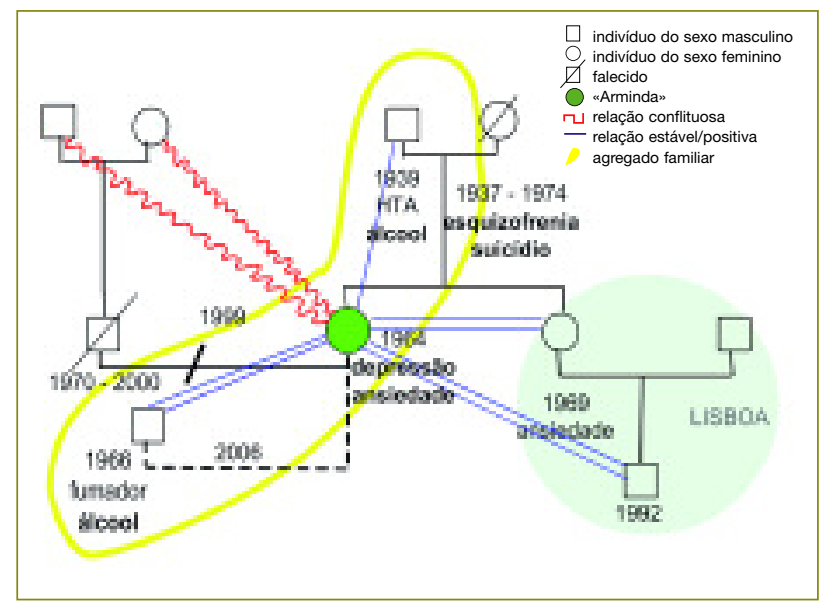

Figura 1. Psicofigura de Mitchell da utente (consulta IV) pouco sabe (ver Figura 1).

$\mathrm{Na}$ altura em que se fez a avaliação familiar (IV), o seu agregado familiar incluía o pai e o companheiro de 39 anos, fumador e com problemas de abuso do álcool, com quem mantinha seis meses de relação.

Os rendimentos do agregado incluíam as reformas da Arminda, do seu pai e do falecido marido. O companheiro era autónomo financeiramente mas não contribuía com dinheiro para as despesas familiares. Para além dos gastos com alimentação, água, luz e gás, grande parte do dinheiro era dispendido em consultas médicas da Arminda e em medicamentos.

O Apgar Familiar de Smilkstein ${ }^{2}$ era baixo (cinco pontos), a classe de Graffar ${ }^{2}$ era média-baixa (IV) e havia médio risco de somatização, quando aplicada a Escala de Risco de Garcia Gonzalez. ${ }^{2}$

Ao desenhar o Circulo Familiar de Thrower ${ }^{2}$ (ver Figura 2), a Arminda incluiu dentro da circunferência o companheiro, a irmã, o sobrinho e o pai e, na periferia, mas fora da circunferência, quatro vizinhas suas amigas.

Avaliou-se o dia típico desta mulher, que se resumia a fazer a lida da casa e companhia ao pai e companheiro. Referiu «pensar muito» e assistir a algumas horas de televisão. Só sai de sua casa para ir a consultas médicas ou para fazer compras, nas imediações da sua casa e nem todos os dias. Referiu não ter interesses ou passatempos.

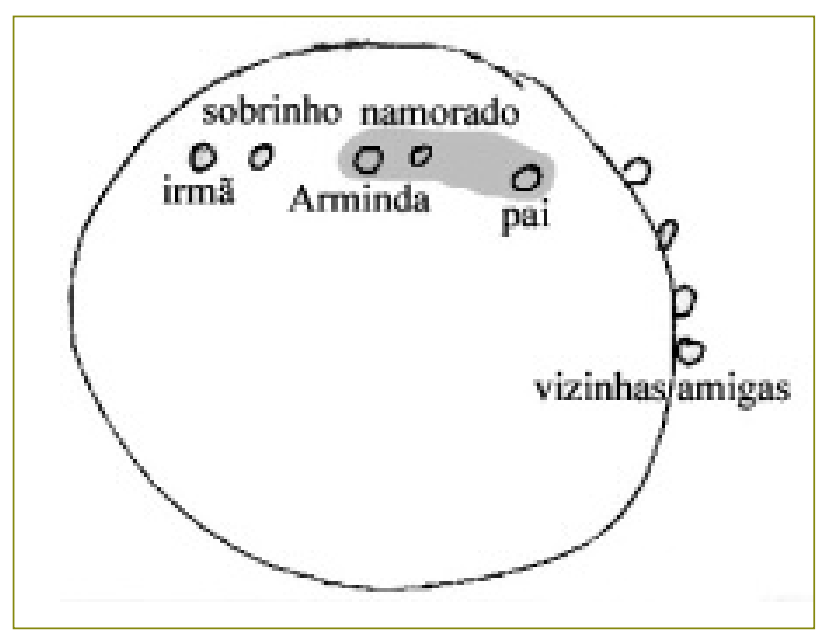

Figura 2. Representação gráfica do Círculo Familiar de Thrower (desenhado pela Arminda na consulta IV).

Foram eliminados da imagem os nomes dos vários familiares, também escritos pela doente, e o registo escrito da data. 
No decorrer da avaliação familiar (IV), surge outra questão: a Arminda manifesta-nos, pela primeira vez, o seu grande desejo de ter um filho. Diz-nos que já tem o apoio do seu companheiro e do seu Psiquiatra. Aguarda a opinião do Médico de Família para, consoante seja positiva ou negativa, avançar ou não para uma gravidez.

Planeia-se com a utente uma consulta de Planeamento Familiar para a semana seguinte, altura em que supostamente poderá vir com o seu companheiro.

Por se considerar a questão da gravidez muito delicada, decide-se pedir opinião a outros colegas, médicos de família mais experientes e psiquiatras antes de responder à utente.

A discussão deste caso entre pares revela-se muito controversa.

Há colegas que antevêem o completo fracasso da gravidez, com consequências graves para a relação entre o casal, a saúde mental da mulher e a saúde da criança. Apontam a falta de condições socio-familiares, a curta duração da relação entre o casal, a instabilidade do humor da mulher e os problemas de alcoolismo e agressividade no agregado familiar como motivos suficientes para desincentivar a gravidez e prescrever uma contracepção mais eficaz, a médio-longo prazo. Acresce ainda o risco decorrente da idade e o facto de a doente, aparentemente, encarar a maternidade como uma possível solução para a sua solidão e o seu desinteresse pela vida.

Por outro lado, há colegas que aconselham uma atitude menos interventiva na dinâmica familiar, dado que nenhum dos antecedentes pessoais da mulher contra-indica formalmente a gravidez. Porque acreditam que a Arminda engravidará mais tarde ou mais cedo, independentemente da opinião do médico de família, defendem que a intervenção clínica deverá ser no sentido de garantir o devido aconselhamento e os cuidados pré-concepcionais.

A responsabilização do casal por uma decisão informada e consciente seria o ideal mas, na prática, é difícil: a Arminda foge à sua responsabilidade na decisão e não conhecemos o companheiro de Arminda, que nem faz parte da nossa lista de utentes, nem acompanha a Arminda às consultas.

As diferentes atitudes ponderadas pelo médico de família parecem potencialmente problemáticas:

- aconselhar a Arminda a não engravidar e a iniciar an- ticoncepção de média duração;

- planear cuidados pré-concepcionais e antecipatórios; substituir fármacos teratogénicos

- informar sobre possíveis dificuldades e mais-valias de uma gravidez e sobre a necessidade absoluta de cuidados pré-concepcionais, mas não interferir na decisão.

A Arminda acaba por voltar à consulta (V) só 3 semanas depois, após convocatória. Apesar de ter sido sugerida a presença do companheiro, vem sozinha. É-lhe explicado que a hipótese de uma gravidez é possível, mas não sem antes tentar a estabilização de uma série de factores. Enumeram-se a curta duração da relação, a incerteza da vontade do companheiro, a incógnita sobre o estado de saúde deste, o ambiente em casa, os problemas com o tabaco e o álcool no agregado familiar, a agressividade do pai, as condições económicas precárias, a falta de apoio familiar e a dependência de alguns medicamentos como potenciais problemas a resolver. ${ }^{3}$ Explica-se que o planeamento dos cuidados pré-concepcionais deve ser feito atempadamente e que há fármacos que terão que ser substituídos ou descontinuados atempadamente. ${ }^{23}$

A Arminda sai visivelmente satisfeita desta consulta e não volta ao CS senão daí a dois meses, para renovação de receituário.

Aproveitamos a oportunidade para conversar com ela (VI) e avaliar os seus planos relativos à gravidez e à contracepção. Nesta consulta, surpreende pela mudança radical de atitude: tem novo companheiro, mostra desinibição sexual, não fala do desejo de engravidar, nem menciona as conversas que manteve em consultas anteriores. Queixa-se de lesão vulvar sugestiva de moluscum contagiosum. É informada do carácter benigno mas muito contagioso da lesão e são aconselhadas medidas de higiene para evitar a disseminação. Planeia-se consulta de PF.

Passados três meses, ainda não tinha regressado à consulta. O MF apercebe-se, através dos registos na rede informática, que a Arminda recorrera, fora do seu horário de atendimento, a uma consulta do Serviço de Atendimento Permanente (VII): apresentou-se convicta de estar grávida do seu novo companheiro e queixou-se de náuseas matinais. Referiu ter engravidado apesar de manter as tomas do anticoncepcional prescrito e de ter tido as hemorragias de privação regulares. «Sabe 
que se pode engravidar mesmo assim». O colega de serviço pediu DIG.

Dado que a situação da pseudociese recorreu, a doente deveria ser referenciada à consulta de Psiquiatria do Centro Hospitalar do Médio Tejo (CHMT), situação que já manifestou não aceitar, em situações anteriores, pois mantém uma relação de confiança com o seu Psiquiatra, fora do SNS.

O MF decide então pedir orientação a um colega psiquiatra do CHMT que, após relato do caso, manifesta a sua opinião no sentido de medicar a utente com um neuroléptico (ex.: haloperidol IM 50 mg depô mensal), já que considera muito provável o diagnóstico de perturbação de personalidade tipo borderline.

Quando a doente voltou ao CS 2 meses depois, para mais uma consulta no SAP (VIII), encontrou o seu MF: tinha retomado a toma da risperidona prescrita pelo seu Psiquiatra e aparentava-se estável do ponto de vista da patologia psiquiátrica, apesar de manter as múltiplas e variadas queixas somáticas que já caracterizavam o seu perfil. Sugeriu-se a marcação de uma consulta de Saúde do Adulto.

Nesta fase do desenvolvimento do caso, o MF planeia uma série de medidas. Destas, destacam-se:

- tentar repor a confiança da utente em si;

- esclarecer o porquê da ida ao SAP e a questão da «nova» gravidez;

- monitorizar a nova terapêutica;

- avaliar o cumprimento da ACO;

- reforçar o ensino sobre o uso de anticoncepcionais orais;

- informar sobre a natureza teratogénica ${ }^{23}$ da terapêutica em curso;

- aconselhar métodos contraceptivos de longa duração e não dependentes de tomas diárias (ex.: implante contraceptivo); ${ }^{23}$

- planear com a doente, a curto prazo, a aplicação de um implante contraceptivo, caso seja essa a sua vontade;

- proceder a nova sensibilização sobre as IST;

- reforçar a importância do uso de métodos contraceptivos de barreira, independentemente do uso de contracepção hormonal;

- questionar sobre a saúde do novo parceiro;

- observar a evolução de lesão sugestiva de moluscum contagiosum;
- avaliar a necessidade de serologias para as IST após período janela;

- perguntar o parecer da utente sobre a troca de informação clínica com o seu Psiquiatra;

- contactar o Psiquiatra para discussão do caso clínico e concertação da terapêutica (Quadro II).

\section{COMENTÁRIO}

Foram referidos como motivos de interesse deste relato: o facto de se tratar de um desafio clínico com várias vertentes controversas; o facto do perfil da utente se ter revelado problemático; o facto da avaliação familiar ter influenciado muito as decisões e o facto de não ter havido consenso entre pares numa questão ética.

\section{UM DESAFIO CLÍNICO}

A pseudociese, ou gravidez «falsa» ou «fantasma», como também pode ser denominada, pode ser enquadrada, neste caso, em dois contextos muito diferentes.

Por um lado, pode equivaler a uma perturbação somatoforme ${ }^{4,6,15-17} \mathrm{e}$, assim, per se, não constituir contra-indicação para uma futura gravidez; $;^{5}$ por outro, pode ser considerado um delírio de gravidez ${ }^{6}$ sobreposto a uma situação de amenorreia secundária e, assim, constituir mais um sintoma psicótico no contexto abrangente de um Distúrbio de Personalidade Borderline, ${ }^{7}$ do qual se podia suspeitar após a avaliação da história pessoal e familiar da utente e do seu perfil psicológico. Neste caso, a contra-indicação da gravidez é menos controversa. $^{6}$

Sumariamente, a pseudociese, como perturbação somatoforme, ${ }^{4,6,15,16}$ refere-se ao aparecimento de sintomas de gravidez sem que esta exista na realidade..$^{5,6,8,17}$ Os sintomas mais frequentes são a sensação de aumento do volume abdominal, as irregularidades menstruais e a sensação de movimentos fetais. ${ }^{17-19}$ Existem várias teorias para explicar os fenómenos. ${ }^{19} \mathrm{~A}$ pseudociese pode também cursar com alterações hormonais decorrentes de desequilíbrios no eixo hipotálamo-hipofisário, das quais a hiperprolactinémia é a mais frequente. ${ }^{5,6,8,17}$

Pode-se limitar ao aparecimento passageiro de sintomas ou, em casos extremos, chegar a durar as 40 semanas da suposta gravidez e culminar num parto «fantasma». ${ }^{8,19}$

Em risco estão as mulheres que vivem o desejo intenso ou, pelo contrário, o terror de uma gravidez. As 


\begin{tabular}{|c|c|c|c|}
\hline $\mathbf{N}^{\circ}$ & $\begin{array}{l}\text { Tipo de } \\
\text { Consulta }\end{array}$ & Relação temporal & Resumo do SOAP \\
\hline 0 & PF & 3 meses antes de I & $\begin{array}{l}\text { Início de relação «estável». } \\
\text { Prescreve-se ACO. Planeia-se consulta de PF para daí a } 6 \text { meses. }\end{array}$ \\
\hline I & NP & Início do relato & $\begin{array}{l}\text { Sinais e sintomas de gravidez. } \\
\text { Pedem-se exames. Planeia-se consulta de Saúde Materna. }\end{array}$ \\
\hline II & NP & 2 semanas após I & $\begin{array}{l}\text { Exames excluem gravidez. Mantém amenorreia e sintomas. } \\
\text { Pedem-se doseamentos hormonais }\end{array}$ \\
\hline III & PF & 2 semanas após II & $\begin{array}{l}\text { Doseamentos hormonais normais. } \\
\text { Recusa fazer teste de provocação com progestativo. Prescreve-se ACO. }\end{array}$ \\
\hline IV & PF & $\begin{array}{l}1 \text { mês e } 1 \text { semana } \\
\text { após III }\end{array}$ & $\begin{array}{l}\text { Teve hemorragia de privação. Acredita não estar grávida. Mantém ACO. } \\
\text { Avaliação familiar. Manifesta vontade de engravidar. } \\
\text { Planeia-se nova consulta de PF. Sugere-se a presença do companheiro. } \\
\text { Discute-se caso clínico com colegas MFs. }\end{array}$ \\
\hline V & PF & 3 semanas após IV & $\begin{array}{l}\text { Falta à consulta planeada. Vem a esta consulta sozinha, após } \\
\text { convocatória. Conversa sobre a possibilidade de engravidar. } \\
\text { Planeia-se nova consulta de PF com a presença do companheiro. }\end{array}$ \\
\hline VI & NP & Cerca de 2 meses após $V$ & $\begin{array}{l}\text { Faltou à consulta planeada. Vem para renovação do receituário. } \\
\text { Mudança de atitude. Sente-se bem. Novo companheiro. } \\
\text { Não fala na hipótese de engravidar. Mantém ACO. }\end{array}$ \\
\hline VII & $A C$ & Cerca de 3 meses após VI & $\begin{array}{l}\text { É observada no SAP por outro médico, que nos relata que Arminda estava } \\
\text { convicta de estar grávida e pediu exames para confirmar gravidez. } \\
\text { Discute-se o caso clínico com o Psiquiatra. }\end{array}$ \\
\hline VIII & $A C$ & Cerca de 2 meses após VII & $\begin{array}{l}\text { Vem ao SAP por agravamento de problema articular. Aparente estabilidade } \\
\text { psicológica. Medicada pelo seu Psiquiatra com risperidona. } \\
\text { Planeia-se consulta de SA para avaliação global. }\end{array}$ \\
\hline
\end{tabular}

Resumo das consultas constantes na descrição do caso clínico.

Legenda: PF - consulta de Planeamento Familiar; NP - consulta não planeada; SAP - consulta no Serviço de Atendimento Permanente; SA - Saúde do Adulto; ACO - anticoncepção oral.

perturbações do humor concomitantes agravam a possibilidade de ocorrer esta situação.

Desde a generalização do uso dos meios complementares de imagem na gravidez (ecografias obstétricas de rotina) a pseudociese tornou-se muito rara.$^{6} \mathrm{~A}$ maioria dos, poucos, relatos que se encontram na bibliografia refere-se a ocorrências em países em desenvolvimento ou em populações não abrangidas pelos cuidados médicos na gravidez actualmente generalizados. $^{8}$

O controlo da situação passa pela psicoterapia e pelo controlo da depressão/ansiedade subjacentes. Apesar da existir a possibilidade de recorrência, o prognóstico é favorável. 5,6

Neste caso, não seria de excluir a hipótese de a doen- te já ter tentado engravidar, já que era esse o seu desejo íntimo. A terapêutica com valproato de sódio, ao reduzir o número de ovulações, ${ }^{23}$ poderá ter impedido o consumar desse desejo, facto que a doente provavelmente desconhece. A ansiedade relacionada com a possibilidade de engravidar ou o facto de não conseguir engravidar poderia ser um factor predisponente para esta perturbação somatoforme.

Em relação à Perturbação da Personalidade Borderline, ${ }^{7}$ é de referir que é uma patologia com uma prevalência de cerca de dois por cento na população geral. ${ }^{9}$

Dadas as características dos doentes (dependentes, conflituosos, não cumpridores, com temperamento instável, inconsequentes, sedutores, manipuladores e sempre insatisfeitos), ${ }^{7}$ as perturbações da personalida- 
de - sobretudo as não diagnosticadas - encontram-se muito associadas, na bibliografia, ao chamado «doente difícil», ou doente «que causa desconforto ao médico».9,10

As mesmas características contribuem, nestes doentes, para uma maior susceptibilidade para as comorbilidades do foro psiquiátrico, os acidentes e a marginalidade. ${ }^{9,7}$

Como causas deste quadro sintomático são apontados: um «esforço frenético para evitar um abandono real ou imaginado» e uma sensação de um enorme «vazio interior», 7 que urge a cada momento "preencher», muitas vezes, sem olhar a meios.

Têm risco acrescido os indivíduos com antecedentes familiares de patologia psiquiátrica ou história de abandono, sobretudo na infância, ${ }^{7}$ como foi o caso desta doente.

Os sintomas surgem geralmente no início da idade adulta, sendo baixa a taxa de incidência após os 40-50 anos de idade. Os doentes estão em risco acrescido de suicídio, com taxas estimadas que podem ser da ordem dos 20 por cento. ${ }^{79}$ No caso da Arminda, a própria mãe consumou o suicídio aos 37 anos.

O prognóstico desta perturbação é reservado. Se não for instituída terapêutica com neurolépticos, os sintomas psicóticos tendem a agravar.

No parecer da autora, a questão basal a reter é que ambas as hipóteses diagnósticas são plausíveis, e a escolha entre elas varia muito com a forma como, neste caso, se avaliam as atitudes da doente. O que é, no limite, a desinibição sexual? O que é uma relação de curta duração? O que é uma mudança «patológica» de parceiros sexuais? A utente é manipuladora? É sedutora? É conflituosa?

Na bibliografia, está bem demonstrado que a experiência clínica e o perfil pessoal e moral do próprio médico pesam possivelmente mais nesta avaliação ${ }^{11-14} \mathrm{do}$ que as próprias atitudes do doente, sobretudo no limite entre o normal e o patológico.

Assim, quando se fala de sinais e sintomas do foro psicológico e de questões relativas à dinâmica familiar, as particularidades psicológicas do médico podem ser determinantes na percepção e interpretação dos problemas, conduzir a diferentes avaliações da mesma situação e condicionar atitudes terapêutica, muito díspares.
Como se viu neste caso, uma gravidez poderia estar pendente neste tipo de avaliação.

O acompanhamento continuado da doente poderá ajudar o clínico a fazer uma avaliação mais apurada da verdade e menos dependente das suas ilações. Seria assim possível estabelecer um diagnóstico mais correcto, se bem que a médio prazo.

\section{O PERFIL DA UTENTE}

Numa Medicina em que, cada vez mais, se sente a pressão das estatísticas, dos custos e da «produtividade» no dia-a-dia da consulta, uma doente que vem à consulta mais do que uma vez por mês e sempre com múltiplas queixas e novos pedidos de exames torna-se problemática. Pelo tempo que é necessário para esclarecer todas as queixas e pelo investimento que é feito em investigações, numa atitude, por vezes, defensiva. Ainda mais se se tratar de uma «doente difícil», que quando vê goradas as suas expectativas reage «contra» o médico. $^{10-14}$

No ponto de vista da autora, seria muito importante aumentar a oferta de formação que capacitasse os jovens médicos de família para a melhor gestão do tempo de consulta e para a gestão de conflitos, como seja a recusa de pedidos inadequados ou a reacção perante atitudes manipuladoras, chantagistas ou sedutoras por parte dos utentes. Na bibliografia encontram-se explicadas múltiplas estratégias para lidar com os diferentes «tipos» de dificuldades. A maior parte das técnicas centra-se no fomento da escuta activa, no estabelecimento de uma maior empatia com o doente e na compreensão das suas expectativas e das suas prioridades em termos de saúde, sem no entanto abdicar da correcção na prática clínica. ${ }^{12,13}$

\section{A IMPORTÂNCIA DA AVALIAÇÃO FAMILIAR}

Neste caso, a avaliação familiar trouxe grandes vantagens e mostrou algumas limitações.

Como vantagens, importa realçar que constituiu uma óptima ferramenta para ajudar na compreensão do caso (ex.: Linha de Vida de Medalie, Escala de Risco de Garcia-Gonzalez) e para sistematizar informações que, de outra forma, poderiam não ser questionadas.

No caso dos testes em que é necessária a colaboração da doente para além de respostas verbais (ex.: desenhos no Círculo de Thrower), houve alguma dificul- 
dade em explicar à doente a dinâmica pretendida e o resultado gráfico obtido deu, de alguma forma, informação discordante daquela que a doente verbaliza. Por exemplo, a representação do pai surge muito próxima da da doente, apesar dos problemas no seu relacionamento (relação escassa/agressividade). Se, por um lado, o facto pode reflectir um erro na compreensão do procedimento no desenho, por outro, pode ser o resultado da ambiguidade da própria relação.

A tentativa de construir um genograma foi também gorada, já que a doente não foi capaz de disponibilizar a maior parte das informações relativas aos seus familiares, dos quais se mantém, salvo a excepção da família da irmã, muito afastada e desinteressada.

\section{O PROBLEMA ÉTICO}

As questões éticas para as quais não se encontrou consenso entre pares foram o motivo principal para a publicação deste relato. Mais do que a consumação de uma opinião, que seria sempre pessoal, da autora, incluem-se várias questões finais, com objectivo de trazer alguns tópicos à reflexão dos colegas.

- Qual o papel do médico de família no caso de uma mulher nulípara, de 43 anos, com os antecedentes de patologia psiquiátrica e a situação familiar descritos, que deseja intensamente engravidar? Neste caso e dada a idade da doente, a resolução virá naturalmente, pela passagem do tempo, mas não deixa de ser uma questão fulcral.

- No caso de se suspeitar de Perturbação de Personalidade Borderline, sabendo que os traumas de infância são dos principais factores de risco, até que ponto a anamnese deve explorar a fundo a história da infância, num momento em que a doente se encontra estável, do ponto de vista psiquiátrico?

- Qual a legitimidade do médico para interferir na decisão de engravidar de uma doente, quando ainda não há certeza do diagnóstico psiquiátrico de base e se sabe que as crenças e opiniões pessoais do médico poderem interferir no seu juízo clínico?

- Como fugir ao problema da «falsa responsabilização»? Segundo o Princípio da Autonomia do doente, um indivíduo autónomo é aquele que está na posse das suas faculdades mentais e capaz de tomar decisões. ${ }^{20}$ Caso isso não se verifique, será o representante legal deste a decidir, e nunca o médico, que apenas poderá aconselhar, expondo os riscos e os benefícios de cada atitude. Depois da doente tomar a decisão (correcta ou não, do ponto de vista do médico) o problema pode surgir quando a doente «responsabiliza» o médico pela sua atitude. Apesar de não ter valor legal, o médico pode sentir-se desconfortável com esta «falsa responsabilidade»/sentimento de culpa e sair pessoalmente prejudicado. As características do próprio médico (a autoconfiança, a experiência, etc...) acabam por ditar o impacto do problema. ${ }^{13}$

- O que fazer quando há um médico completamente envolvido mas à margem do processo? Neste caso, temos um médico psiquiatra da total confiança da doente, fora do SNS, com o qual não há qualquer contacto nem troca de informação clínica, para além do que a doente nos pede ou transmite. Importa não interferir na relação terapêutica de confiança que a doente mantém com o médico, mas é de evitar aceder a todas as exigências não fundamentadas, por exemplo, de exames complementares de diagnóstico. Este equilíbrio nem sempre é pacífico e é a confiança da doente no MF que se perde quando as expectativas da doente (legitimadas pela prescrição de outro médico) não são conseguidas.

- Durante a investigação deste caso, o MF deparou-se com a diferença entre a sua hipótese diagnóstica para a patologia psiquiátrica da utente e o diagnóstico do Psiquiatra para a mesma situação (perturbação do humor, reactiva e em remissão), com consequentes diferenças nas opções terapêuticas. A juntar a estas, surge, da parte do Psiquiatra do SNS a quem apresentamos o caso clínico, a hipótese diagnóstica de Perturbação de Personalidade Borderline. Como proceder nesta situação? Na opinião da autora, o colega fora do SNS deveria ser contactado para troca de informação clínica relevante, tentativa de chegar a acordo sobre a terapêutica e a plano de monitorização da mesma. Caso não se consiga contactar o colega e se verifique manutenção ou agravamento dos sintomas, a opção de medicar com o antipsicótico sob orientação de outro psiquiatra será válida? E quem fica responsável pela monitorização dessa terapêutica?

\section{CONCLUSÕES}

Na prática, a autora acredita que algumas modificações 
na conduta do MF poderiam dar a este caso clínico um rumo mais favorável. Entre essas, destaca:

- A avaliação familiar poderia ter sido mais precoce, já que a utente tinha o perfil de utilização das consultas e o tipo de queixas sugestivos de disfunção familiar desde praticamente a sua inclusão na lista de utentes. Esta avaliação permitiria perceber o risco de somatização da utente e acompanhar os seus problemas com mais atenção.

- A avaliação das expectativas pessoais da utente perante a maternidade poderia ter sido avaliadas precocemente no âmbito da consulta de Planeamento Familiar, independentemente do seu estado marital ou de ter ou não parceiro sexual.

Na opinião da autora, essa avaliação deveria ser feita inicialmente a todas as utentes da consulta de Planeamento Familiar/Saúde da Mulher e repetida sempre que surgissem novos problemas ou terapêuticas que alterassem a possibilidade de engravidar ou que pudessem ser erradamente interpretados pelas utentes como tendo um impacto importante nessas expectativas.

- Poder-se-ia ter apostado na educação da utente sobre como diferenciar sintomas agudos, que obrigam a observação médica urgente, de sintomas agudos sem gravidade e sintomas decorrentes das suas afecções crónicas que podem ser controlados em casa e observados em consulta programada.

- Após instituídas as medidas de educação mencionadas, poderia ter sido tentado um plano de consultas programadas individualizado para a Arminda, inicialmente com consultas mais frequentes, que progressivamente se poderiam ir espaçando mais no tempo.

- O colega Psiquiatra da utente poderia ter sido contactado precocemente no desenrolar deste episódio para se esclarecer melhor a história psiquiátrica desta utente.

- A discussão interpares de casos clínicos «difíceis», ao invés de situações avulsas, discutidas com um colega de cada vez, mediante o interesse e a «boa vontade» de cada um, poderia ser instituída no CS como parte de uma reunião clínica semanal ou quinzenal com espaço e horário próprio, independentemente de haver ou não trabalhos a apresentar aos colegas. Tal como a exposição do erro em medicina, a aceitação e exposição das dificuldades dos clínicos perante os seus pares ainda conta com múltiplas barreiras «culturais» próprias da classe. As vantagens deste tipo de reuniões clínicas são conhecidas e estão bem documentadas. ${ }^{21}$

Discutir um caso clínico difícil entre pares permite usufruir da sensibilidade, experiência profissional e pessoal de cada um dos presentes, obter novos pontos de vista e conseguir uma perspectiva mais abrangente da situação a resolver. Para além dos benefícios na resolução dos casos clínicos em si, esta discussão interpares é uma mais valia que contraria o problema do «isolamento profissional» associado à especialidade de MGF. ${ }^{11,21,22}$

\section{REFERÊNCIAS BIBLIOGRÁFICAS}

1. Chan PD, Johnson MT. Treatment Guidelines for Medicine and Primary Care. Laguna Hills, CA: Current Clinical Strategies Publishing; 2006. p. 307-9.

2. Caeiro RT. Registos clínicos em Medicina Familiar. Lisboa: Instituto de Clínica Geral da Zona Sul, 1991.

3. Cepêda T, Brito I, Heitor M.J. Promoção da saúde mental na gravidez e primeira infância: Manual de orientação para profissionais de saúde. Lisboa: Direcção-Geral da Saúde; 2006.

4. American Psychiatric Association, Diagnostic and Statistical Manual of Mental Disorders (DSM IV). Washington; DC: American Psychiatric Association; 2000. p. 230.

5. Sadock BJ, Sadock VA. Somatoform Disorders. In: Kaplan \& Sadock's Comprehensive Textbook of Psychiatry. 7th ed. Philadelphia, PA: Lippincott Williams \& Wilkins; 2000. p. 1504-32.

6. Brockington I. Obstetric and gynaecological conditions associated with psychiatric disorder. In: Gelder MG, Lopez-lbor Jj, Andreasen N (editors). New Oxford Textbook of Psychiatry. Oxford: Oxford University Press; 2003.

7. American Psychiatric Association, Diagnostic and Statistical Manual of Mental Disorders (DSM IV). Washington, DC: American Psychiatric Association; 2000. p. 292.

8. Whelan $\mathrm{Cl}$, Stewart DE. Pseudocyesis: a review and report of six cases. Int J Psychiatry Med 1990; 20 (1): 97-108.

9. Gross R, Olfson M, Gameroff M, Shea S, Feder A, Fuentes M, et al. Borderline personality disorder in primary care. Arch Intern Med 2002 Jan 14; 162 (1): 53-60.

10. Schafer S, Nowlis PD. Personality Disorders among difficult patients. Arch Fam Med 1998 Mar-Apr; 7 (2): 126-9.

11. Steinmetz D, Tabenkin $H$. The 'difficult patient? as perceived by family physicians. Fam Pract 2001Oct; 18 (5): 495-500.

12. Haas LL, Leiser JP, Magill MK, Sanyer ON. Management of the difficult patient. Am Fam Physician 2005 Nov 15; 72 (10): 2063-8.

13. Essary AC, Symington SL. How to make the «difficult» patient encounter less difficult. JAAPA 2005 May; 18 (5): 49-54.

14. Bremberg S, Nilstun T, Kovac V, Zwitter M; GPs facing reluctant and demanding patients: analysing ethical justifications. Fam Pract 2003 Jun; 20 (3): 254-61. 
15. American Psychiatric Association, Diagnostic and Statistical Manual of Mental Disorders (DSM IV). Washington, DC: American Psychiatric Association; 2000. p. 229.

16. American Psychiatric Association, Diagnostic and Statistical Manual of Mental Disorders (DSM IV). Washinghton, DC:American Psychiatric Association; 2000. p. 231.

17. Zuber T, Kelly J. Pseudocyesis. Am Fam Physician 1984 Nov; 30 (5): 131-4 .

18. Moulton R. The psychosomatic implications of pseudocyesis. Psychosom Med 1942 Sep-Oct; 4 (4): 376-88.

19. Paulman PM, SadatA. Pseudocyesis. J Fam Pract 1990 May; 30 (5): 575$-6$.

20. Stirrat GM, Gill R. Autonomy in medical ethics after O'Neill. J Med Ethics 2005 Mar; 31 (3):127-30.

21. Fragata J, Martins L. O erro em medicina. Coimbra: Almedina; 2004.

22. Missão para os Cuidados de Saúde Primários; Linhas de Acção Prioritária para o Desenvolvimento dos Cuidados de Saúde Primários; Resolução do Conselho de Ministros n. ${ }^{\circ}$ 157/2005, de 12 de Outubro. Diário da República, n. ${ }^{\circ} 196$, I Série B.
23. O'Brien MD, Gilmour-White SK. Management of epilepsy in women. Postgrad Med J 2005 May; 81 (955): 278-85.

24. Isojärvi J, Laatikainen TJ, Pakarinen AJ, Juntunen KT, Myllylä VV. Polycystic ovaries and hyperandrogenism in women taking valproate for epilepsy. N Engl J Med 1993 Nov 4; 329 (19):1383-8.

\author{
ENDEREÇO PARA CORRESPONDÊNCIA \\ Margarida Mesquita \\ R. Silva Magalhães, 20 - 2300-593 Tomar \\ Telf: 249566816 ou 934253611 \\ E-mail:mar.mes@gmail.com
}

\section{AGRADECIMENTOS}

Leonor Prata, Médica de Família no Centro de Saúde da Reboleira Marta Sattut, Médica de Família no Centro de Saúde do Entroncamento

Recebido em 18/04/2008

Aceite para publicação em 27/06/2008

\section{ABSTRACT}

This case was considered important to publish because it was a clinical and ethical challenge with various controversial points, the patient was considered «difficult» and the familiar approach was important to reach conclusions about the diagnosis and clinical procedure.

The report is about a 43 years old woman with a heavy psychiatric precedent history who presents amenorrhoea and symptoms of being pregnant. After demonstration of no pregnancy with normal clinical examination and various complementary diagnostic tests, she maintains her firm conviction on her pregnancy and refers maintenance of the amenorrhoea, pregnancy symptoms and feelings of «the baby moving» for four more months. Meanwhile, she refers her desire of getting pregnant.

In this case, because of her precedent psychiatric history, the diagnosis of pseudocyesis is not clear. It may be considered an isolated somatization disturb or, in the other hand, a delusion, part of a very complex psychiatric problem of borderline personality, determining different approaches for the pregnancy hypothesis.

This nuliparous woman, widowed and retired, with heavy familiar and personal psychiatric history, lives with her father and recent boyfriend, both with alcohol abuse related problems. She asks her family doctor for consultation about 15 times a year, always with renewed complaints and claims frequently for new diagnostic exams and analysis, maintaining manipulative manners and transferring the responsibility of her health decisions to the doctors.

The psychiatric diagnosis, the therapeutic approach and the pre-conceptional counselling were discussed with other family doctors and psychiatrists, without reaching any consensus.

Keywords: Pseudopregnancy, Pseudocyesis, Pregnancy Wish, Familiar Dysfunction, Pre-conceptional Counselling, Borderline Personality. 